\title{
Computational medicinal chemistry: part II
}

"This issue features a mixture of reviews and original research covering the broad and ever-expanding range of computational tools available to the pharmaceutical scientist."

We are delighted to introduce the second instalment of this thematic series dedicated to computational medicinal chemistry [1].

Chemists often lament the perceived failure of combinatorial chemistry and other technologies in which much hope was once invested, to deliver high-quality candidates for lead optimization [2]. Consequently, in the 'postcombinatorial era' attention has increasingly focused on the application of computer-based approaches in drug discovery and design. As the Guest Editor of this thematic series, Gisbert Schneider, observed in the introductory foreword, "there is ample evidence that computational medicinal chemistry has become an indispensable pillar of modern drug research" [1].

This issue features a mixture of reviews and original research from renowned experts in the field, covering the broad and ever-expanding range of computational tools available to the pharmaceutical scientist [2-4].

\section{In this issue}

The design of high-quality screening collections is of crucial importance for early-stage drug discovery. Renner et al. highlight recent efforts to expand access to bioactive chemical space [5]. They draw on observations from high-throughput screening campaigns, recent successes in chemogenomics and diversityoriented synthesis, as well as nonclassical approaches, such as fragment-based screening and DNA-encoded chemical libraries. Bryce explores current strategies for physicsbased scoring of protein-ligand affinity and, in addition, outlines recent developments in force fields and quantum chemical techniques, touching on prospects for the further integration of higher accuracy physics-based approaches at earlier stages in computationally guided drug discovery [6]. The approaches employed in computer-aided drug design (CADD) distil into two major categories: structure-based and ligand- methods. Wilson et al. discuss the methods that have resulted in recent years following efforts to integrate these two methods in order to enhance the reliability and efficiency of CADD approaches by combining information from both the ligand and the protein [7]. Tautermann discusses the use of in silico receptor models in lead optimization in light of the emergence of new crystal structures of G-protein coupled receptors [8]. Tuccinardi considers RNA molecules as therapeutic targets and, in particular, the docking of RNA-binding ligands [9]. He analyzes the development of RNA docking approaches and the reliability of the docking methods, before evaluating the results of docking-based virtual screening studies reported in the literature. The structurebased design of small-molecule inhibitors of protein-ligand and protein-protein interfaces is currently receiving much attention. Koch discusses how similarities in binding sites and protein interfaces, even in unrelated proteins, can be used to predict polypharmacology and inspire novel drug design [10].

Bruno et al. investigate the serotonin receptor 5-HT2A, an antipsychotic drug target that forms functional homodimers and heterodimers with the mGluR2 receptor, with a view to building 3D models of the $5-\mathrm{HT} 2 \mathrm{~A} / \mathrm{mGluR} 2$ heterodimer and of the 5-HT2A/5-HT2A homodimer [11]. Johansson et al. set out to compare several state-of-the-art methods for generating accurate models with methods for generating transparent models, using results from 16 biopharmaceutical classification tasks.

We hope that the articles featured in this issue of Future Medicinal Chemistry provide useful insights into the valuable contributions being made by computational approaches to the advancement of pharmaceutical science.

\section{Acknowledgements}

Special thanks go to Gisbert Schneider for serving as Guest Editor for this thematic series.

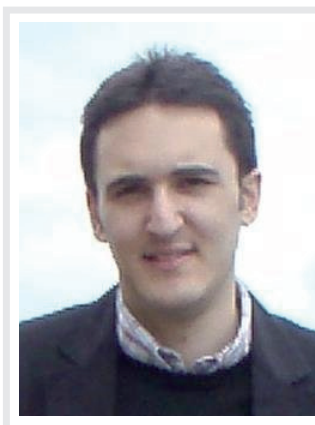

\section{Gino D'Oca}

Commissioning Editor

Future Science Group, Unitec House, 2 Albert Place, London, N3 IQB, UK

Tel.: +4420 8371 6080

Fax: +44 2083716099

E-mail: g.doca@future-science.com 


\section{Financial \& competing interests disclosure}

Gino D'Oca is an employee of Future Science Group. The author has no other relevant affiliations or financial involvement with any organization or entity with a financial interest in or financial conflict with the subject matter or materials discussed in the manuscript apart from those disclosed.

No writing assistance was utilized in the production of this manuscript.

\section{Bibliography}

1 Schneider G. Computational medicinal chemistry. Future Med. Chem. 3(4), 393-394 (2011).

2 Ojima I. Medicinal chemistry at a crossroads: challenges and new possibilities. Future Med. Chem. 1(3), 401-403 (2009).

3 Rabal O, Urbano-Cuadrado M, Oyarzabal J. Computational medicinal chemistry in fragment-based drug discovery: what, how and when. Future Med. Chem. 3(1), 95-134 (2009).
4 Skjevik ÅA, Teigen K, Martinez A. Review of computational methods employed in early-stage drug discovery. Future Med. Chem. 1(1), 49-63 (2009).

5 Renner S, Popov M, Schuffenhauer A et al. Recent trends and observations in the design of high-quality screening collections. Future Med. Chem. 3(6), 751-766 (2011).

6 Bryce, RA. Physics-based scoring of protein-ligand interactions: explicit polarizability, quantum mechanics and free energies. Future Med. Chem. 3(6), 683-698 (2011).

7 Wilson GL, Lill MA. Integrating structurebased and ligand-based approaches for computational drug design. Future Med. Chem. 3(6), 735-750 (2011).

8 Tautermann, CS. The use of G-protein coupled receptor models in lead optimization. Future Med. Chem. 3(6), 709-721 (2011).

9 Tuccinardi, T. Binding-interaction prediction of RNA-binding ligands. Future Med. Chem. 3(6), 723-733 (2011).
10 Koch O. Use of secondary structure element information in drug design:

polypharmacology and conserved motifs in protein-ligand binding and protein-protein interfaces. Future Med. Chem. 3(6), 699-708 (2011).

11 Bruno A, Beato C, Costantino G. Molecular dynamics simulations and docking studies on $3 \mathrm{D}$ models of the heterodimeric and homodimeric $5-\mathrm{HT}_{2 \mathrm{~A}}$ receptor subtype. Future Med. Chem. 3(6), 665-681 (2011).

12 Johansson U, Sönströd C, Norinder U, Boström H. Trade-off between accuracy and interpretability for predictive in silico modeling. Future Med. Chem. 3(6), 647-663 (2011). 